\title{
Challenges Confronting Clinicians in Acute Care
}

\author{
Dr Vicki Parker, RN, PhD \\ Clinical Nurse Consultant Research \& Practice Development, Nursing \& Midwifery Centre for Practice Opportunity \& Development (CPOD).HNE Health
}

Michelle Giles, RN CM, B. Bus. MIS

Clinical Nurse Consultant Research, Practice Development \& Information Technology, CPOD. HNE Health

Prof Isabel Higgins RN PhD,

Professor of Nursing Older Person Care.University of Newcastle \& HNE Health

\begin{abstract}
Aim: The study aimed to identify current challenges confronting health care professionals and to use this information to develop priorities for practice change projects.

Method: A 3 phase mixed method design, incorporating descriptive and interpretive approaches was utilised. Data were collected via questionnaire, focus groups and nominal group workshops.

Results: Communication, skill-mix and work environments were identified as issues of most concern. Participants were able to identify and prioritise a range of projects they believed would help to better understand and alleviate problems within the workplace.

Conclusion: There is an urgent need for improved efficiency around all forms of communication, to reduce interruptions to care, and to reduce anxiety experienced by staff who feel they are unable to provide good care.
\end{abstract}

Key words: Challenges, communication, workplace, skill-mix, resources.

\section{INTRODUCTION}

This study was designed to better understand the local acute care work environment and to inform the research direction for the newly established Nursing and Midwifery Centre for Practice, Opportunity and Development (CPOD). The Centre was established in the Greater Newcastle Cluster of Hunter New England Area Health Service in November 2006 with three main priorities: to provide leadership for research and practice development; to create impetus for change; and to challenge and assist nurses to adopt contemporary evidencebased practice.

The context of acute care practice is varied, dynamic and increasingly complex. Further, current practice environments are characterised by increasing differentiation and patient acuity, an aging staff and patient population, staff shortages and increasing numbers of non-graduate nurses with various levels of education (Shah \& Burke, 2002; McMillan, Conway \& Fitzgerald, 2004: Jackson \& Daly, 2004). Within this context, the nature and scope of nurses' roles, functions and responsibilities need to be critically evaluated and revised to meet contemporary challenges.

The current crisis in recruitment and retention in nursing has led to much work in identifying areas critical to the achievement of effective and satisfying contemporary nursing practice (McMillan, Conway \& Fitzgerald, 2004). These include workforce issues; models of care; evidence-based decision-making; and reflective practice (McMillan, Conway \& Fitzgerald, 2004; Jackson \& Daly, 2004). A study conducted in 2002 by the New South Wales Nurses' Association to determine reasons why nurses were leaving the profession identified the multi-factorial and relational nature of nurses' discontent. Nurses participating in that study expressed the view that the work they do is valued by managers for its efficiency and cost saving, rather than its quality and meaning to patients. They reported feeling more challenged and less supported in a role they see as less clearly delineated and increasingly complex (Buchanan \& Considine, 2002).
Health professionals feel the value of their work is diminished when efficiency is given primacy over quality of care. Shannon \& French, (2005) identified managerialism as one of six trends impacting on health professionals and health care in Canada. Other trends include a shift from quality patient care to safe patient care, a shift of nurse managers into non-nursing positions, regulation of workload, demand for increased public accountability, politicisation of healthcare and healthcare administration, increased consumer participation in planning and running health care and a crisis in human health care resources. Similar trends have been identified in Australia (Wellard, Liilibridge, Beanland \& Lewis, 2003). Whilst these and many other issues impacting on health professionals and their work are clearly highlighted in the literature, there is little attention as to how they impact at ward and practice level and across contexts. At this more fundamental level, factors such as communication, role clarity and work practices contribute to patient outcomes, efficiencies, staff satisfaction and motivation.

Cultural change can only be achieved through re-visioning and revising the nature of health professionals' work, through strengthening interdisciplinary relationships and relationships with patients and their families (Jones \& Cheek, 2003). It is imperative to understand the challenges facing health professionals and to build their capacity to meet them. In order to help nurses improve their practice and hence patient outcomes it is important to understand the experiences and concerns of clinicians at all levels, as well as relationships between disciplines and how these impact on patient care.

The aim of this research was to contextualise this information by engaging clinicians in the process of identifying issues of most concern to them. Previous studies in the field (Jones \& Cheek, 2003; Fagin, 2001) have used interviews or focus groups alone whereas the present study has further explored information by involving clinicians in a workshop designed to analyse data gained from surveys and focus groups. Clinicians were invited to discuss the data and make decisions about what projects should be undertaken to help overcome identified problems. 
There were three main purposes of the study. They were to:

- Identify challenges confronting health care professionals in acute care settings and perceived priorities for practice change;

- Use a consultative, participatory research process; and

- Generate a profile of projects that will facilitate improved patient outcomes and staff participation, and build research and practice change capacity at ward and unit level.

\section{METHOD}

The research utilised a 3 phase mixed method (quantitative and qualitative) inductive design, incorporating descriptive and interpretive approaches.

- $\quad$ Phase 1 involved the development, distribution and analysis of a survey questionnaire.

- Phase 2 involved focus groups using questions drawn from the analysis of the returned questionnaires.

- $\quad$ Phase 3 involved workshops using nominal group technique to identify potential projects which may be implemented to address problems highlighted in the survey and focus groups.

Participants included enrolled nurses, registered nurses, nurse mangers, nurse consultants, educators, doctors and members of allied disciplines across the sector. Approval to conduct the study was gained from Hunter New England Area Health Service Human Research Ethics Committee

\section{Phase 1: Questionnaire/survey}

The questionnaire was developed, piloted and modified based on feedback regarding content, clarity of questions and instructions and sequencing of questions. Twelve items asked for information regarding demographics, years of service, issues of concern (prioritised) impact on patient care and impact on personal/professional experience. Required responses were either tick boxes or short answer.

Following information sessions conducted across 24 wards and units, surveys were left on the ward for staff to fill out anonymously and returned to the Centre for Practice Opportunity and Development (CPOD). Of these, 85 surveys were returned to the research team.

\section{Phase 2: Focus Groups}

The aim of the focus groups was to better understand issues arising from the survey data. In particular, in the focus groups participants:

1. Examined in depth the most significant issues identified in the survey;

2. Examined relationships between issues identified in the surveys; and

3. Provided examples of how issues/problems occurred and impacted their ward or unit.

Three focus groups were convened with five to seven participants in each session and each session was of 60 to 90 minutes duration. Participants were asked to consider a set of questions derived from the survey responses. The questions asked participants to focus on the four most identified issues arising from the surveys and their impact on patient care and clinical practice in their ward or unit. These issues were communication, staffing, working life and resources.

Focus group participation was broadly representative with RNs (casual and full time), clinical nurse consultants (CNCs), nurse managers, physiotherapists and dieticians. In total, 20 staff were involved in focus groups over one month. In accordance with ethical requirements, all participants gave permission for the discussion to be taped and transcribed.

\section{Focus group analysis}

Transcripts were analysed to elicit themes and identify examples from clinical practice given by the participants that strongly supported and illustrated the themes. The transcripts were analysed by various members of the research team and compared for reliability and consistency. Findings were then compared with those found in the existing literature to identify findings that were either consistent with or different from other studies.

\section{Phase 3: Workshops}

Workshops were conducted over two weeks with 22 people, half of whom had participated in the focus groups. The aim of the workshops was to use information gleaned from the surveys and focus groups as stimuli to generate ideas about what projects could be used to address the issues identified as most in need of attention. Nominal group technique was used to identify projects considered most important and most likely to be successful.

To make it easier for workshop participants, the research team decided to work with the main categories identified in the survey and to use examples from focus groups as stimuli. The two highest ranking issues were communication and those related to staffing and skill-mix. Whilst the other categories are important, the purpose of the workshop was to prioritise issues, therefore working with the highest ranking issues was a logical step. However, the categories are not mutually exclusive and therefore there is still scope for projects which recognise the inter-relationship between categories.

Participants were given a single page summary of findings related to communication and staffing and skill mix and three to four pages of exemplars from focus group transcripts. Three sets of exemplars were developed, one from each focus group. These were distributed so that equal numbers of people were working with the same information and all focus groups were represented.

Participants were given time to read the material during the workshop and to identify what they saw as the most significant issues. They were asked as individuals, to identify ways in which these issues could be addressed and to outline a project they felt might contribute to improvement. Working in small groups, participants were then asked to prioritise projects put forward by their group members.

Finally, the larger group worked together to discuss and prioritise projects to identify the top ten projects. These were then rated against a range of criteria, including significance, ability to be implemented and perceived risks to success. Scores were then collated to identify which projects should be worked up as research or practice development projects. 


\section{RESULTS}

A total of 85 surveys were returned. It is not possible to estimate the response rate as a percentage as there was no identified target number. Rather, questionnaires were left on the ward for people to complete and return at their discretion.
Even though the return rate was low relative to staff numbers, they came from a wide distribution of areas and from a broad range of staff, representing all the major multidisciplinary groups, including nurses, doctors, physiotherapists and dieticians. Sixty percent of those who returned questionnaires were in fulltime permanent employment. Survey responses were categorised according to a general area of concern.

Table 1. Survey responses

\begin{tabular}{|c|c|c|}
\hline Category & Details & $\%$ \\
\hline Communication & $\begin{array}{l}\text { Poor interdisciplinary communication, poor hierarchical communication, handover, } \\
\text { miscommunication and conflicting information provided to patients and relatives. } \\
\text { Poor quality and inconsistent information. }\end{array}$ & 20 \\
\hline Staffing issues & $\begin{array}{l}\text { Skill mix, staff shortages, rostering, increasing numbers of staff, increasing demand } \\
\text { for mentoring and staff procurement. }\end{array}$ & 19 \\
\hline Working Life & $\begin{array}{l}\text { Lack of flexibility in rosters, lack of job satisfaction. Not being able to do your job } \\
\text { properly, despair with lack of focus on patient care, stress, and workload. } \\
\text { Encroachment of work into private family life (working late, overtime, and being } \\
\text { called to come to work on days off). } \\
\text { Not being able to take annual and other leave in accordance with family needs. }\end{array}$ & 14 \\
\hline Resources & $\begin{array}{l}\text { Not enough basic equipment (pillows, linen, thermometers and BP machines). Lack } \\
\text { of maintenance of equipment. Hoarding and not sharing equipment. }\end{array}$ & 14 \\
\hline $\begin{array}{l}\text { Staff attitudes and } \\
\text { behaviours }\end{array}$ & $\begin{array}{l}\text { Lack of collegiality. } \\
\text { Negativity. } \\
\text { Apathy. Failure to respond to bad behaviour. Culture of business and blame. } \\
\text { Feeling disregarded and under valued. }\end{array}$ & 8 \\
\hline Education and Support & $\begin{array}{l}\text { Lack of financial and in-kind support for higher education. Lack of opportunity for } \\
\text { further education, particularly conference leave. }\end{array}$ & 6 \\
\hline $\begin{array}{l}\text { Patient and family } \\
\text { issues }\end{array}$ & $\begin{array}{l}\text { Client behaviour, increased acuity of patients, increased aggression, increased } \\
\text { incidence of mental health problems, increased obesity. } \\
\text { Increased expectations. }\end{array}$ & 6 \\
\hline Leadership & $\begin{array}{l}\text { Lack of leadership, emphasis on throughput and other KPIs, lack of planning, } \\
\text { reactive management. } \\
\text { Lack of support and understanding from management. }\end{array}$ & 6 \\
\hline Environment & $\begin{array}{l}\text { Unclean and cluttered, shabby, lack of appropriate space for staff and relatives. } \\
\text { Unbearable conditions for patients and staff in hot weather. }\end{array}$ & 4 \\
\hline Miscellaneous & Difficulties with parking. & 3 \\
\hline
\end{tabular}

\section{Focus group findings}

Themes arising from the focus groups transcripts included adjusting to change, living with restrictions, the challenge of skill mix, constant chaos, disconnection and uncertainty and it's not all bad. Underpinning these themes was a combination of particular concerns and tensions relating to communication, staffing, quality of care and patient outcomes, working life and lack of resources.

\section{Adjusting to change}

This describes the challenges arising from constant and intense change. Participants indicated that an organisational paradigm shift towards service, efficiency, managerialism and accountability, together with shrinking resources, particularly staff was a major impetus driving change. As a consequence, staff felt pressured to adjust by working faster and harder, compromising their values and learning to cope with uncertainty. Whilst change was viewed as challenging, it was not seen as all negative, rather participants agreed that change was necessary and in some instances long overdue. What were seen as challenging and disappointing about change were not being involved in and not being informed about the process, and seeing no benefit from change projects. Conflict and dissonance result from having to reconcile competing demands, values and expectations.

The current fragmentation of service delivery across wards, together with staff and workload issues mean that wards and staff are often segregated and no longer aware of the needs and circumstances of others.

There has also been a change in the expectations of patients and families. Participants were torn between feeling imposed upon by unrealistic expectations on the one hand and feeling unable to meet patients' very basic needs on the other.

As one nurse explained:

It is difficult because of people's expectations these days. They are often very unrealistic or just misguided and to accommodate that is not always easy or practical. It's frustrating that you are doing all you can, but their expectation is that they deserve more and need more.

Another nurse expressed a view that:

People did feel better looked after [in the past], I am sure. You 
know their teeth were cleaned, their bums were rubbed and whether or not that is now contradicted, they felt better.

\section{Living with restrictions}

Participants identified how their capacity to be effective in their work was diminished by having to live with restrictions. Essentially they included lack of time, lack of staff with a high level of expertise and lack of resources, equipment and information. Some also identified lack of support from management.

Although participants generally agreed that lack of time was a significant problem some also identified lack of prioritisation as problematic. Having more to do across the course of a shift results from increased patient acuity, greater demands from patients and relatives and greater managerial emphasis on efficiency and throughput. Loss of control over the what, when, how and how much time practitioners can devote to tasks prevents them from having a sense of direction and completion. Instead, the flow of the day is punctuated by disruptions that distract staff from the successful accomplishment of the sets of activities they had originally planned for the day:

It is race in, do the job and walk away. Don't get involved, don't encourage conversation because you haven't got the time to put the effort in and that is quite sad.

Taking time away from your patients you know, what are we here for, patient care? Instead we spend half an hour each shift moving beds.

Managers and senior staff struggle finding enough staff to meet daily staffing requirements. Further, they feel a strong sense of responsibility and a degree of desperation when their numerous attempts to find staff are unsuccessful:

That's how the nursing shortage has virtually made us, it's like, can you please come to work, I'll give you anything you want, it really makes it hard to provide the coverage and adequate coverage of skill mix.

Nonetheless, permanent staff working overtime is seen as more effective than employing casual staff in that the staff are experienced and familiar with the ward, the types of patients and work practices. Further, it means team leaders are not continually on the phone looking for staff and it also helps overcome some of the unpredictability and complexity associated with staffing needs. It is this complexity that participants agreed creates at times an overwhelming sense of being unable to control workload, work conditions and patient care:

Just because there are four staff for example in the morning and its going very nicely you can't guarantee that the same number of staff the next day is going to, it all depends on the people who are coming through the doors.

Across the organisation participants described an increase in the numbers of casual and less qualified staff. This change impacts on the nature of the work and responsibility of all staff. Many participants agreed that often having new and inexperienced staff made their jobs more difficult. Others understand that without new recruits there will be no long term solution. There was much discussion in the focus groups about the pros and cons of employing casual staff, enrolled nurses and AINs. The following conversation is an example:

We have got a few casuals that will come into work there but its very daunting I guess to turn up to a unit where you're 'it'. You don't have anyone to ask. Where do I find this? There are a few casuals who come regularly and can cope with it but it takes a fair bit of orientation to get them to that stage where they feel comfortable.

To the point now where we have a larger amount of that type of staff compared to registered staff so that being able to mentor them is very difficult.

\section{Constant Chaos}

Participants describe a work environment that is characterised by constant high levels of activity where resources are continually stretched. However, often unforseen events and spurts of increased demand move wards and units into overload where there are simply not enough beds, staff and other resources to provide the required care. At this point, over-run and overflow in one area impacts on units and staff in other areas. Patients are unable to progress through the system, and increased demand for service cannot be supported by the necessary staff, equipment and support services.

In situations of continuing crisis participants firmly believe that the safety of patients is at risk:

They said that I was in charge that I have got an enrolled nurse to work with me on the afternoon shift even though I had never stepped foot into a ward. I had no idea what was going on.

Chaos is characterised by over-run, access block and the presence of outliers. In the chaos, systems that were designed to cater for a specific number of patients with particular health problems and needs are required to manage different patients with different needs and who would normally be connected to an established communication network that facilitated their care and progress through the hospital system:

When you get outliers it is very confusing chasing down teams, and when you have got say a cardiology patient sitting in a medical ward or a surgical patient sitting in a medical ward it is extremely difficult to get the doctors up there and to review that patient and to tell us what they want done.

Even though they feel patients are at risk by being placed in the wrong ward, staff feel powerless to do anything about it. Participants provided many examples of how inadequate staff numbers and in particular inexperienced staff led to poor outcomes for patients and stress for themselves:

Today I was the only RN on and I had three ENs. One of them could give out their medications, the other two couldn't. Two of those ENs were casuals who didn't know the ward. We had two arrests, one death.... and one fellow fell in the shower and hit his head, he had a bleed and just yeah (sigh), but you haven't got experienced staff.

Adding to the chaos is the lack of equipment, either because there has not been enough time to restock or the level of activity had exceeded expected demand for stock:

I mean the whole ward ran out of everything, needles, syringes, giving sets, we had nothing. We were running to and fro to other wards.

\section{Disconnection and uncertainty}

This describes how participants are unable to provide continuity of care for their patients. This inability arises from lack of time, not having all the information necessary to 
provide holistic care and fragmentation of the patient's hospital experience. Poor communication is at the crux of the issue, with all modes of communication being poorly executed. In particular, participants highlighted communication between doctors and nurses, between allied health staff and nurses, between families and staff, poor or absent documentation and inability to access computers. Poor communication was one of the key problems seen to diminish quality of working life for staff:

We still have an ongoing issue with communication between them writing in the notes, like the doctors writing in the notes what they want done and then also verbally going up to the nursing staff, even the dieticians and physios doing the same thing, going up, and then verbally telling the nurses what they want done.

Our communication breakdown is probably more between what we are doing and what the nurses are doing or trying to get direction from the doctors.

Handover was cited frequently as the most dysfunctional aspect of communication. There is inconsistency in the way handover is managed. Some wards used computer generated sheets where information was standard and changed very little from day to day. In other wards handwritten notes were passed from shift to shift with items crossed out and others added. Others used audio-taped handovers which people felt saved time but failed to allow for questions which were often crucial to understanding a patient's situation. Some participants were exasperated with the amount of irrelevant and often inappropriate conversation that occurred during handover. All felt pressured by the need to get handover over and get out on the floor to begin to assess their workload and meet their patients' immediate needs:

You have got to try and sort it out or look in notes or go searching for information, you know a lot of it isn't written down, a lot of it is word of mouth.

Handover to each other was not a problem identified by allied health. However they shared with nursing staff the frustration of poor communication by medical staff who often failed to let anyone know that they had seen a patient and made adjustments to their medical treatment:

Our doctors do not do regular ward rounds; the specialist will just turn up, see the patient, and write the notes and go.

They [doctors] speak to the nursing staff if they know them and are happy to tell them but otherwise you read it in the notes, it's a big problem on our ward too.

Not having information places clinicians in a difficult position where they are unable to act with authority and to speak with confidence to patients and their relatives. Being unable to speak with authority to patients and their families undermines the building of a trusting relationship, often resulting in a situation of scepticism, anger and disharmony:

And they say 'but you told us that we could go home in the morning', or they will say 'you will get a private room when you come up to the ward', they don't' tell us that. Or a nurse the shift before will say 'your child can't have a drink' or 'your child can't do this' and the next one comes on and says 'yeah that's alright they can do that' and then you have got these parents who are all over the shop. They get angry then they start causing hassles for nurses.

Participants also feel disconnected from the organisation, when decisions are often made without consultation and when they have very little connection with other ward areas. The resultant isolation prevents people from seeing the big picture and working together collaboratively:

There is not much communication between the wards and levels, the whole hospital is very fragmented, and it's very insular.

Each department is siloed, working across all of the areas we find it very difficult to know who to communicate with and the fact that one area does not talk to the other area.

At the ward level the day-to-day continuity of care was disrupted by constant interruptions to the delivery of care. Interruptions included phone calls, requests from other staff and patients and emergencies of varying scales. Such interruptions meant that frequently clinicians had not been able to achieve their plan for the day and aspects of care were left unattended. Nurses, in particular were distressed by having to leave work for colleagues on the following shift.

\section{Quality of working life}

The combination of factors already discussed impact on the working life of staff and many feel frustrated by lack of regard for them as people, lack of flexibility, increased demand on their time, intrusion into their personal time and space, and increased stress resulting from lack of control over the quality of care they provide to patients.

Some feel tormented by the organisation, when even on days off they are pressured to do extra shifts:

I had four days off recently and I had at least a half a dozen phone calls to come into work. I shouldn't have to turn my mobile phone off, not that I want to avoid work, but they don't just give up, they persist and I know they are short staffed, but it gets to a point where I don't care, this is not my problem. I am full time and I have already worked seven to midnight the other night.

I feel really frustrated. You know I wake up in the morning and think about what I've got to do today. I better go in half an hour early and more often than not I will be here an hour or an hour and a half later to get everything done.

You could live, eat, work, die here and no one would even know that you have ever existed. And it is quite true... no it is quite true.

Perceived lack of acknowledgement and regard for staff, poor communication and inefficiency adds to frustration. Many motivated staff find it difficult to further their careers and to contribute to the profession in the way they would like and in the way they believe is necessary to support change. They are frustrated by lack of financial support and study leave:

\section{Some small amount of recognition would make a difference, even} if it were simply a thankyou.

I mean don't get me wrong, our NUM (Nurse Unit Manager) is fantastic and our senior staff are fantastic in supporting us but you are really getting no recognition, no rewards, no benefits, no nothing from the department, management, the hospital for anything that you do.

Some participants were disappointed by lack of fairness, suggesting that not everyone was treated in the same way. However, their discussion indicated understanding of the difficulties associated with rostering and the invidious position of the NUM in attempting to recruit and retain staff: 
People will go on forever about unfairness of rostering, you know, some people don't work weekends and some people don't work night duty, you know some people get exactly what they want to work, other people fill in wherever and I think that really upsets people.

I heard in our tearoom today a new grad in tears about her roster and I told her to go and speak to her manager but she said "I don't want to upset anybody because I am going to be leaving here soon".

However, effective rostering is not just about satisfying staff needs, getting the mix right is crucial to patient safety as well as staff satisfaction:

If you are on a morning shift and say you have five staff allocated and you will have four CNS's and two year 8's. You will come on an afternoon and you will have one CNS, one year 4, two new grads and an EN and it's that sort of stuff that has a big impact on your work day.

In general, participants believe most staff have a strong commitment to their ward, working a lot of overtime and taking very little sick leave and sometimes having little choice:

One night we were told that you could not go, you had a duty of care to stay. Two of us out of everyone were the only two that had not worked overtime and they were short and they were saying basically you have a duty of care to stay or you lose your registration.

I think everybody has done the number one thing patient care at heart, but it wears a bit thin after a while.

\section{Its not all bad}

This was often the counter balance to the overriding propensity towards negativity in the focus groups. Participants were insistent that the situation was not all bad, that good care was being provided and that in many instances patients were happy with the care they received. Generally they accepted that greater demand on health services has lead to diminished capacity of the organisation to meet the populations' health needs. They see no sense in dwelling on the negative side of things, it won't change anything:

I can't really complain at all except that we don't have enough staff... but that's just the way it is.

You know, you will turn up in the morning and you will have a ward that's full and it's busy but you have got a team that is pulling together and says that we are going to have a good day and you know that you will have a good day and then the family will be happy, staff will support each other.

\section{DISCUSSION}

The findings of this study are consistent with previous national and international research. Increasing demands on nurses' time together with staff shortages are consistent with findings in many studies (Fagan, 2001; Jones \& Cheek, 2003; Geuvara \& Mendias, 2002; Shannon \& French, 2005). Lack of time is relative to workload and of patients' and nurses' expectations of themselves. Without the opportunity to develop a relationship with patients and families, nurses can be perceived as ineffective. Being with people is part of the enjoyment of being a nurse, without rewarding relationships coming to work can become a chore (Jones \& Cheek, 2003).

The study findings also highlight the need for improved efficiency around all forms of communication in order to improve clinical outcomes for patients, improve relations between staff and patients and between various health care disciplines. Finding ways to reduce and/or manage interruptions to care will help improve continuity and reduce anxiety experienced by staff who feel they are unable to provide good care.

Participants were keen to see initiatives that will help reconcile tensions around expectations and values, engaging clinicians collaboratively in change processes. The challenge is that outcomes need to be meaningful for clinicians as well as contribute to the efficient running of the organisation. Research and practice change projects that concentrate on the patients' perspective would help clinicians concentrate on those aspects that are likely to both increase satisfaction and improve relationships. Projects aimed at exploring person-centred approaches to care, where all stakeholders are involved in the design and implementation of change would help to ensure communication and ownership.

There is an urgent need for initiatives that support and strengthen optimism and resilience. Such projects could utilise examples of success and excellence as benchmarks and guidance for others. Projects could be linked to better integration and understanding of mental health as significant for both staff and patient groups. Also given the tensions around leadership, teamwork, communication and competing demands, it is essential to support NUMS in relation to rostering, staffing, procurement and allocation of resources, and fiscal management.

\section{CONCLUSION}

This study has given voice to clinicians' concerns and provided invaluable insight into the complex and demanding nature of clinical practice in acute care settings. It illustrates the tensions experienced by clinicians and the difficulties inherent in a system under pressure of increasing demand.

\section{References}

Buchanan, J. \& Considine, G. (2002). Stop telling us to cope! NSW nurses explain why they are leaving the profession. A report for the NSW Nurses' Association. Sydney, Australian Centre for Industrial Relations Research and Training. University of Sydney: $1-54$

Fagin, C. (2001) When care becomes a burden: Diminishing access to adequate nursing. www.milbank.org/reports/WhenCareBecomesBurden retrieved 14.7.07.

Guevara, E. \& Mendias, E. (2002) A comparative analysis of the changes in nursing practice related to health sector reform in five countries of the Americas. Pan American Journal of Public Health, 12(15), 347-355.

Jackson, D \& Daly, J. (2004) Current Challenges and Issues Facing Nursing in Australia. Nursing Science Quarterly, 17(4), 352-355.

Jones, J. \& Cheek, J. (2003) The scope of nursing in Australia: a snapshot of the challenges and skills needed. Journal of Nursing Management, 11, 121-129.

McMillan, M., Conway, J. \& Fitzgerald. (2004) Issues in workplace, work practice and workforce: Implications for care models and nursing service delivery. Final report of a desktop study commissioned by the Department of Human Services, Victoria.

Shah, C. \& Burke, G. (2002) Job growth and replacement in nursing occupations: Working paper No. 43 Monash University-ACER Centre for Economics and Training, Canberra.

Shannon, V. \& French, S. (2005) The impact of the re-engineered world of health care in Canada on nursing and patient outcomes. Nursing Inquiry, 12(3), 231-239.

Wellard, S., Liilibridge, J., Beanland, C. \& Lewis, M. (2003) Consumer participation in acute care settings: An Australian experience. International Journal of Nursing Practice, 9(4), 255-260. 